\title{
Characterization of ultrafine-grained copper joints acquired by rotary friction welding
}

\author{
M. Ciemiorek ${ }^{1}$ (I) $\cdot$ Ł. Morawiński ${ }^{2} \cdot$ C. Jasiński ${ }^{2} \cdot$ M. Orłowska ${ }^{3} \cdot$ T. Chmielewski $^{2} \cdot$ L. Olejnik $^{2} \cdot$ M. Lewandowska $^{1}$
}

Received: 11 August 2021 / Revised: 12 October 2021 / Accepted: 24 October 2021 / Published online: 12 November 2021

(c) The Author(s) 2021

\begin{abstract}
Copper rods with ultrafine-grained microstructure, obtained by multi-turn ECAP processing, were subjected to Direct Drive Rotary Friction Welding using various processing parameters, such as rotational speed and pressure, which resulted in different energy and heat input. Even though friction welding is a high energy process, by a proper selection of processing parameters it was possible to maintain grain size at around $0.7 \mu \mathrm{m}$ in the weld zone and preserve the UFG microstructure. These microstructural features translated into mechanical properties: the YS for those specimens was around $330 \mathrm{MPa}$. Processing parameters that resulted in a larger heat input caused an increase in grain size to around $2 \mu \mathrm{m}$; this, however, increased ductility and led to a uniform elongation exceeding 5\%. Corrosion resistance in the stir zone increased, as was evident in the higher open circuit potential and higher corrosion potential in comparison with base material; the observed differences were about $50 \mathrm{mV}$. These changes can be explained by the higher fraction of HAGBs in the SZ.
\end{abstract}

Keywords Copper $\cdot$ Ultrafine-grained $\cdot$ Solid state welding $\cdot$ Microstructure $\cdot$ Mechanical properties $\cdot$ Corrosion

\section{Introduction}

Ultrafine-grained (UFG) materials feature extraordinary mechanical properties that make them attractive for industrial applications, although their limited size still limits utilization. The most popular methods of fabrication UFG materials are Severe Plastic Deformation (SPD) processes, which are constrained by the billet size-usually too small for industrial use. Even though there have been some successful attempts at upscaling the processes [1], they require machinery of considerable power. Joining methods, therefore, provide an attractive alternative for manufacturing long products. The two most recognized solid state joining processes known for producing welds

M. Ciemiorek

marta.ciemiorek.dokt@pw.edu.pl

1 Warsaw University of Technology, Faculty of Materials Science and Engineering, Wołoska St. 141, 02-507 Warsaw, Poland

2 Warsaw University of Technology, Faculty of Mechanical and Industrial Engineering, Narbutta St. 85, 02-524 Warsaw, Poland

3 Faculty of Mechanical Engineering, Military University of Technology, Kaliskiego St. 2, 00-908 Warsaw, Poland of high quality are linear friction welding and friction stir welding (FSW), used for joining such objects as sheets or flat profiles, and rotary friction welding (RFW), suitable for axially symmetrical objects [2]. Apart from the obvious implementation of solid state processing methods for joining, they found their use in other applications. In this context friction hydro pillar processing or friction taper stitch welding should be indicated, which are used for crack repair in underwater, high radiation or even explosive environment [3]. Solid state processing can also be used for refining microstructure to UFG regime. Friction stir processing (FSP), a modification of FSW, is particularly effective in obtaining sub-micrometer grain size and higher fraction of high angle grain boundaries in comparison to other SPD methods, which makes it possible to obtain superplastic properties [4]. Among the many advantages of solid-state processes, their low temperature in comparison with traditional welding operations should be emphasised, since it makes them suitable for processing UFG materials [5], which are particularly sensitive to high temperatures. Solid state welding has been successfully applied for joining various UFG materials such as low-carbon interstitial free steels [6], aluminum alloys [7, 8] or magnesium [9], as well as for various combinations of materials, such as pure aluminium with an alloy [10] or 
aluminum with copper $[11,12]$. Studies have also reported on friction joining processes being used for acquiring a UFG microstructure in the weld zone in copper [13] or aluminium $[14,15]$.

Copper is characterized by a relatively high melting point and good thermal conductivity. When joining such conductive materials, heat quickly diffuses into the base material, and so to produce a high-quality solid state joint, a sufficiently large heat input is required [16]. Proper selection of processing parameters of solid state welding of pure copper with conventional grain size was proved to be essential to acquire high quality welds with mechanical properties similar to base material (BM). There are studies available on friction stir welding $[17,18]$ or rotary friction welding [19] of pure copper, which indicate that heat input is a main factor which determines final microstructure and mechanical properties. Studies have shown that reducing rotational speed and temperature of the processes results in decreasing difference of hardness between weld zone and BM from around $45 \%$ to $15 \%[17,18]$ resulting in more uniform mechanical properties of the joint. However, a lack of friction welding trials of UFG copper was observed. Since UFG microstructure is temperature sensitive, substantial heat input can result in grain coarsening, leading to a deterioration in the enhanced mechanical properties resulting from the reduced grain size. To obtain a high-quality joint, it is necessary to optimize the heat input so as to achieve a proper connection between the rods and at the same time prevent excessive grain growth. This is possible when a processing method is chosen in which the heat input can be controlled.

In this article, Direct Drive Rotary Friction Welding (DDRFW) is proposed as a method characterized by relatively low welding temperatures and short welding times [20]. The DD-RFW method, also referred to as continuous drive friction welding, is a method used for joining rods or tubes. During the process, one component is held stationary and a rotating counterpart is pushed against it. The movement of the welded elements induces heat and plastic strain, which leads to mixing plasticized metal and the establishment of a metallic bond. The heat input depends on the relative velocity of the workpieces, the duration of the process, and the compressive axial force [21]. It possible to control the welding conditions, and therefore the microstructure and mechanical properties of the joined material.

In this study, solid state welds of UFG copper rods $11.5 \mathrm{~mm}$ in diameter were characterized, focusing on their microstructure, mechanical properties and corrosion resistance. This last property was examined to reveal changes in particular zones of a weld. The aim of the paper is to review the influence of selected processing parameters of Direct Drive Rotary Friction Welding (DD-RFW) that lead to maintaining properties similar to those of a UFG rod, namely high mechanical strength and microstructural features.

\section{Material processing and experimental}

Copper rods of commercial purity were subjected to six passes of multi-turn Equal Channel Angular Pressing (mtECAP) [22] using an industry standard tooling [23] with an $2 \times 110^{\circ}$ channel, which resulted in the formation of a UFG microstructure [24]. The mtECAP technology is thoroughly described in [25]. Such a rod in UFG condition is referred to in this paper as the BM. Rods were subjected to DD-RFW using various processing parameters on an HWH RSM200 machine. The welding parameters, i.e., the pressure at the friction phase $P_{\mathrm{T}}$ and forging phase $P_{\mathrm{S}}$ as well as the rotational speed $N$, were set on the machine. The resulting time of friction phase $t_{\mathrm{T}}$ and total friction time $\mathrm{t}_{\mathrm{TC}}$, defined as the sum of the friction and braking times, were calculated based on data acquired during the welding process. Based on previous research [26], a processing window of optimum conditions was chosen and samples were welded according to the parameters listed in Table 1. Two parameters were adjusted, i.e., rotational speed and friction phase pressure, which were in a range of $13,000-20,000 \mathrm{rpm}$ and $2.5-4.5 \mathrm{bar}$, respectively, whereas the forging phase pressure was set at 5.5 bar. Various combinations of these parameters resulted in different friction times $\mathrm{t}_{\mathrm{T}}$ and total friction times $\mathrm{t}_{\mathrm{TC}}$. To ensure good joint quality, rods with conical foreheads were used whose angle of inclination was $8^{\circ}$. Figure 1 presents joints S101 and S106 in the as-welded state and their cross sections.

Changes in the mechanical properties within the weld zone were evaluated by performing standard Vickers microhardness measurements with a load of $200 \mathrm{~g}$. Indents were made every $400 \mu \mathrm{m}$ through the cross-section of the weld, parallel to the axis of the rod. To evaluate the mechanical properties, a uniaxial tensile test was performed using a Zwick Roell Z005 universal testing machine equipped with a DIC system for precise strain measurements. The tensile test was conducted at a strain rate of $10^{-3} 1 / \mathrm{s}$. The tensile test specimens, whose geometry is shown in Fig. 2a, were cut using electrodischarge machining from the weld zone, as in Fig. $2 b$.

Table 1 DD-RFW parameters used for joining rods

\begin{tabular}{cllllll}
\hline & \multicolumn{3}{l}{ Pre-set weld parameters } & & \multicolumn{2}{c}{ Resulting time } \\
\cline { 2 - 3 } Joint & $N$ [rpm $]$ & $P_{\mathrm{T}}[\mathrm{bar}]$ & $P_{\mathrm{S}}[\mathrm{bar}]$ & & $t_{\mathrm{T}},[\mathrm{ms}]$ & $t_{\mathrm{TC}}[\mathrm{ms}]$ \\
\hline S101 & 20,000 & 4.5 & 5.5 & & 50 & 150 \\
S113 & 20,000 & 2.5 & 5.5 & & 35 & 205 \\
S203 & 16,000 & 3.5 & 5.5 & & 35 & 135 \\
S106 & 13,000 & 4.5 & 5.5 & & 30 & 135 \\
S110 & 13,000 & 2.5 & 5.5 & & 45 & 195 \\
\hline
\end{tabular}



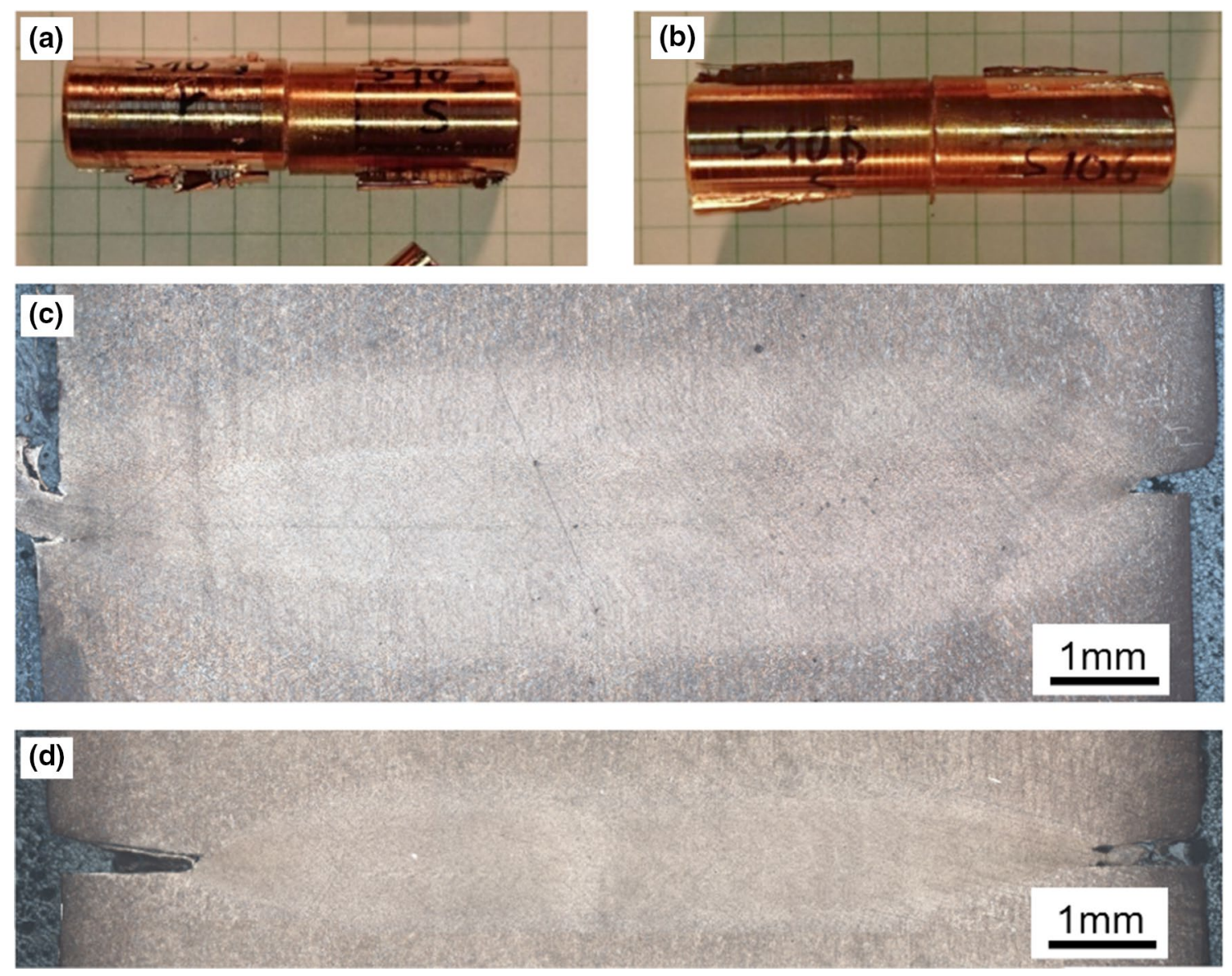

Fig. 1 Photographs of welded rods S101 (a) and S106 (b) and their longitudinal cross sections (rotated at 90 ${ }^{\circ}$ ) (c) and (d), respectively

(a)

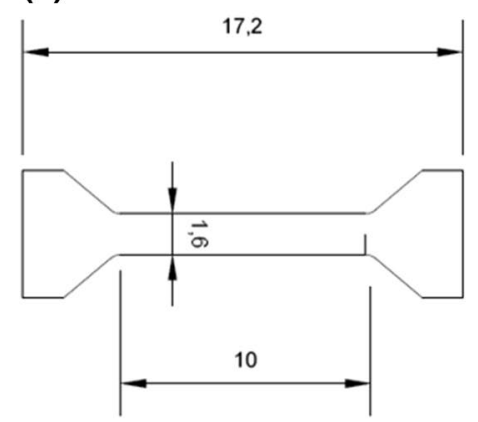

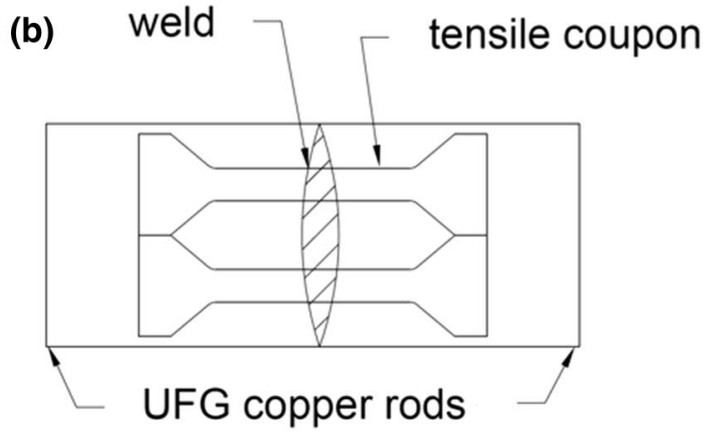

Fig. 2 Tensile test specimen dimensions (a) and its position on the welded rods (b)

The microstructure investigation was based on EBSD mapping, and was performed on a Hitachi Su-70 analytical SEM with a Schottky emitter and an acceleration voltage of $20 \mathrm{kV}$, equipped with an HKL Channel 5 system. Observations were made at the center of the weld at the rod's axis, indicated in Fig. $2 b$ by the hatched area. The samples for the EBSD observations were electropolished using a perchloric acid ethanol solution. The microstructure was quantitively characterized based on the equivalent grain size d, defined as the diameter of a circle having an area equal to that of a specific grain. The maps were analyzed using Channel 5 software. To ensure the clarity of the maps, misorientations of grains greater or equal to $3^{\circ}$ were taken into account. In the EBSD maps, Low Angle Grain Boundaries (LAGBs), 
i.e., those between 3 and $15^{\circ}$, are marked by white lines, whereas High Angle Grain Boundaries (HAGBs), defined as $>15^{\circ}$, are black. Each color represents a specific grain orientation according to the legend provided in Fig. $3 \mathrm{~g}$.

Corrosion resistance was examined based on open circuit potential (OCP) and potentiodynamic polarization (PP) tests. The electrochemical experiments were carried out at room temperature in a $3.5 \mathrm{wt} . \% \mathrm{NaCl}$ bath using an AutoLab PGSTAT32 N potentiostat/galvanostat. A conventional three-electrode cell was used, with a platinum wire as the counter electrode and a silver chloride electrode as the reference electrode. The OCP was observed over $30 \mathrm{~min}$ of immersion in the test solution. PP scans were initiated at $0.1 \mathrm{~V}$ below the OCP. The OCP was measured for the base material (BM) and the stir zone (SZ) of each weld. In the case of the PP, additional experiments were performed for the heat-affected zone (HAZ). For both examinations, the surface of the working electrode was $0.07 \mathrm{~cm}^{2}$. Representative curves are given in Figs. 9 and 10.

\section{Results and discussion}

\subsection{Microstructure of the welds}

EBSD maps representing microstructure of $\mathrm{BM}$ and stir zone (SZ) of joins are presented in Fig. 3. The initial UFG copper rod is characterized by a grain size of $0.70 \pm 0.18 \mu \mathrm{m}$, with $47 \%$ of HAGBs. The microstructure is illustrated in Fig. 3a, showing well-developed grains, defined by black lines, inside which LAGBs are present. Such a microstructure indicates that there is a high density of subgrains inside the well-developed ones, characterized by HAGBs. Such microstructure is typical for copper processed by ECAP using route $B_{c}$ at middle stages of processing [27]. UFG copper rod was subjected to four passes through the $2 \times 110^{\circ}$ channel, which was not sufficient to acquire distribution of misorientation angles similar to random. During ECAP processing, grains are rotated, therefore at the initial stage there are many LAGBs present, which are later rotated to HAGBs, reaching saturation after eight passes of conventional ECAP [28]. Therefore, intermediate fraction of HAGBS at four passes of mt-ECAP processing is consistent with the above findings. This is reflected in the distribution of misorientation angles, shown in Fig. 4, where a higher frequency is displayed for the LAGBs. The random distribution of misorientation is represented by the dashed line showing the Mackenzie line.

The microstructure of joints S101, S113 and S203, presented in Fig. 3b-d, is substantially different than the UFG base material. The grain size increased, reaching $1.81 \pm 1.50$, $1.99 \pm 1.54$ and $1.25 \pm 0.74 \mu \mathrm{m}$, respectively, as shown in
Fig. 4b. The number of LAGBs decreased, which is visible as a reduction in the amount of white lines inside the grains. Therefore, the fraction of HAGBs increased to 74,87 and $72 \%$. As indicated in Fig. 4a, this increase can be attributed to the high frequency of the misorientation angle of $60^{\circ}$, which is typical for twin boundaries, especially for the $\mathrm{S} 113$ joint, and to a decrease in the number of LAGBs due to the decrease in the number of subgrains. Grain coarsening, typical for friction welding processes, is caused by an increase in sub-boundary misorientations due to a continuous accumulation of dislocations caused by plastic deformation, which then rotate, coalesce and transform into larger grains characterized by HAGBs [29]. For materials having a low stacking-fault energy (SFE), such as $\mathrm{Cu}$, which are subjected to high strains, discontinuous dynamic recrystallization may be the main mechanism leading to grain coarsening [30]. The microstructure of joints S106 and S110 underwent fewer changes in comparison to the BM. The grain size decreased slightly for S106, down to $0.67 \pm 0.29 \mu \mathrm{m}$, and increased for S110, reaching $0.82 \pm 0.33 \mu \mathrm{m}$. The fraction of HAGBs increased to $79 \%$ and $75 \%$, respectively, with a slight shift towards the Mackenzie plot. For coarse grained copper subjected to FSP, dynamic recrystallization leads to fine equiaxed grains with low dislocation density and distribution of misorientation angles close to random [32]. Similar results are shown in this study, as all presented microstructures feature fine grains close to $1 \mu \mathrm{m}$, and very low fraction of LABGs, a type of microstructure typical for dynamic recrystallization [31].

During friction welding, microstructural changes occur in the material due to the supply of energy that transforms into heat [33]. Modelling the thermal processes taking place during friction welding is a complex issue, since during solid state welding heat is generated due to plastic deformation, friction, and rapidly changing strain rates, speed and friction coefficient [34]. Energy can be defined as the sum of supplied heat power $Q$ with a constant period $T$, which is dependent on the sampling frequency of the measuring system during friction time $\mathrm{t}$ (see Eq. 1). The value of $Q$ results from parameters that vary during the process, i.e., the rotational speed $N$, the radius of the conical forehead $r$, and the axial force $F$. Therefore, to take those changes into account, the formula presented in Eq. 2 is proposed. In the initial stage of the process, the friction coefficient $\mu$ also changes significantly. During extremely short welding times, it is very difficult to determine the instantaneous values of the friction coefficient, and so a mean value was adopted at a level of $\mu=0.3$, based on the data showing the change in the friction coefficient with rotational speed [34], friction time, and other parameters [35].

$$
E=\sum_{0}^{t} Q T
$$



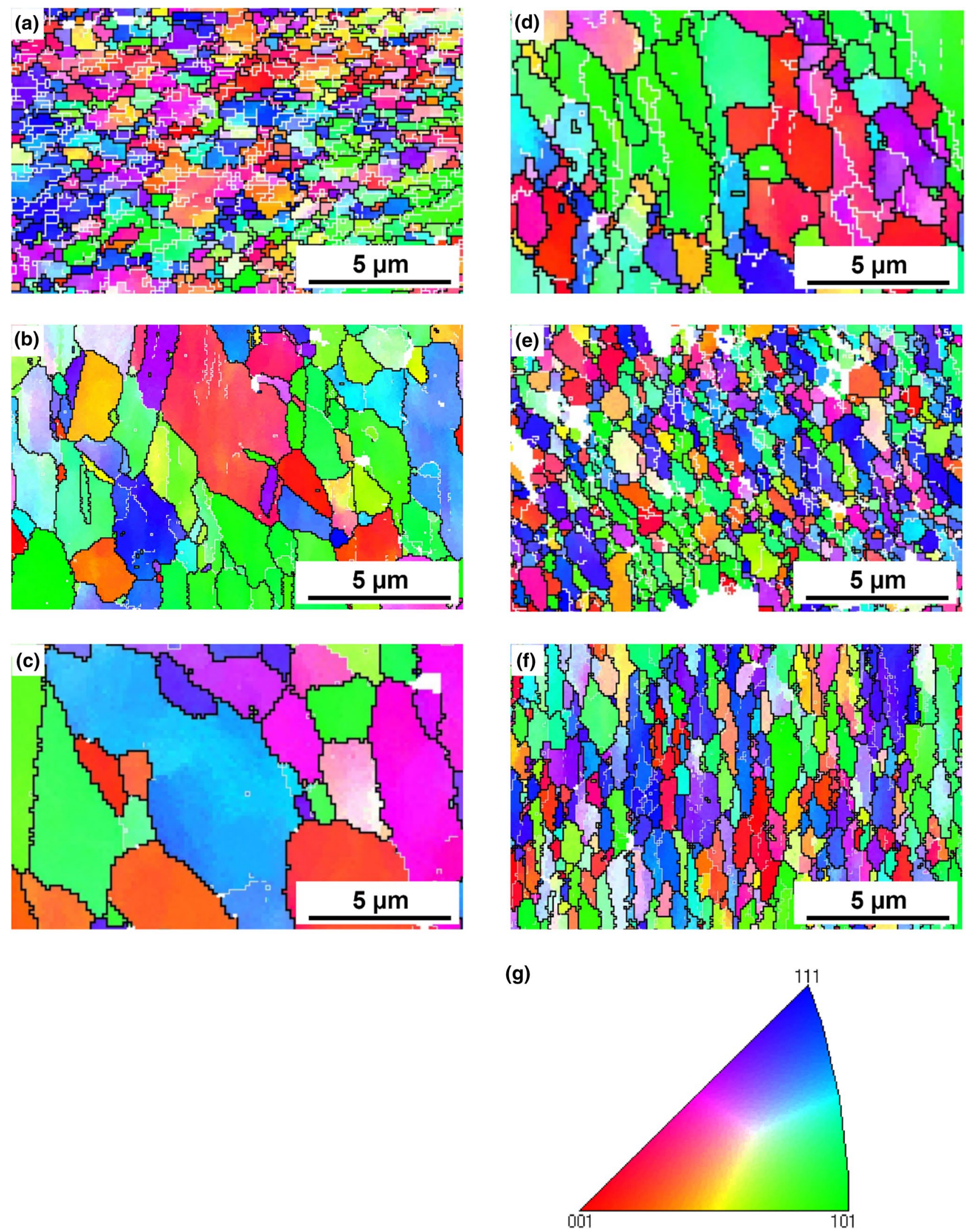

Fig. 3 EBSD maps of SZ of the base material (a) and joints S101 (b), S113 (c), S203 (d), S106 (e), S110 (f) and legend presenting Inverse Pole Figure coloring scheme (g) 

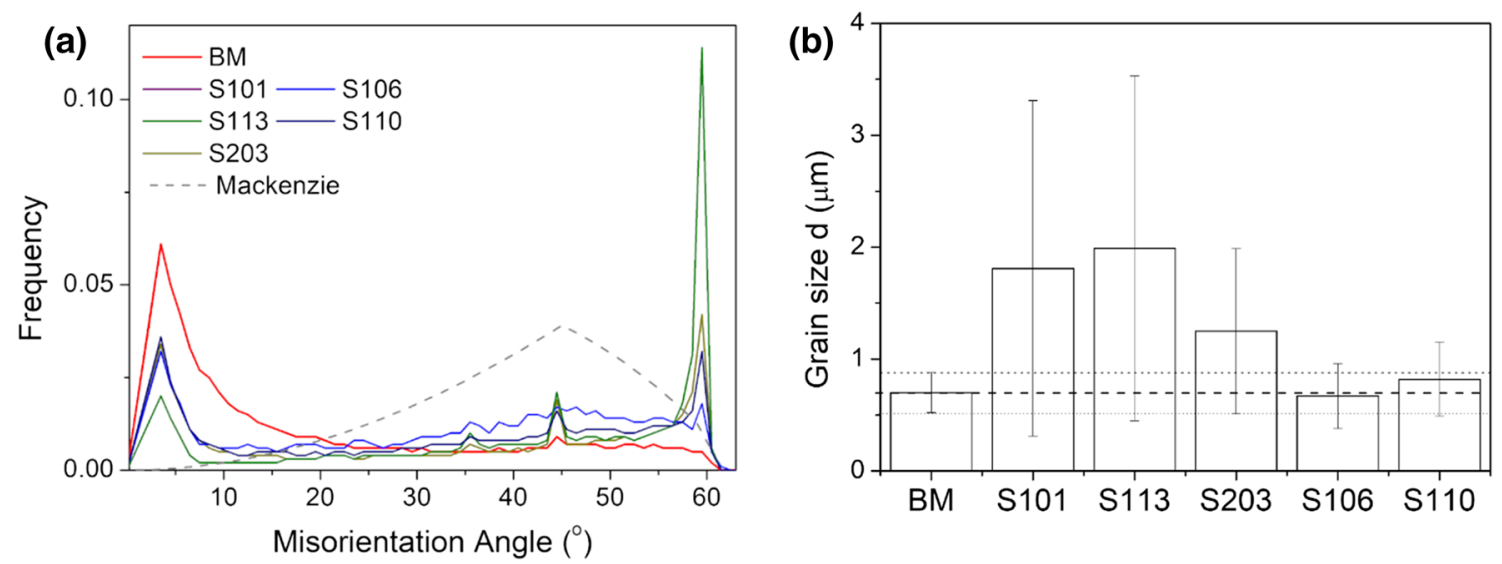

Fig. 4 Misorientation angle distribution of joints compared to the BM and Mackenzie plot (a), grain size d of the joints investigated (b); the dashed line shows the average grain size of the BM and the dotted line its standard deviation

$Q=\frac{2}{3} \mu \operatorname{Fr} \frac{\pi N}{30}$

The changes observed in the microstructure of the welds are dependent on the energy, i.e., the amount of heat, that was supplied to the material. The welding conditions of joints S101 and S106 differed only by parameter $N$, which was 20,000 and $13,000 \mathrm{rpm}$, respectively, and which translated to differences in in energy and heat values in accordance with Eqs. 1 and 2. Based on the results, it can be stated that a change in rotational speed significantly affected the energy value and resulted in substantial grain growth in joint S101. A similar trend was observed for joints S113 and S110, whose processing conditions also differed only by $N$, while increasing the rotational speed led to more significant grain growth in S113. Increasing the rotational speed also results in larger friction and a longer total time, increasing the energy supplied, which was more than twice as high for S113, which increased the heat and led to grain growth. The joints in which grain size did not change significantly in comparison with the BM were S106 and S110. These were welded using the lowest rotational speed. The grain size of S106 is even slightly lower than that of the BM. This joint was made using the lowest rotational speed and shortest welding time among those analysed. There are many studies suggesting that it is possible to even refine microstructure using processes in which a material is stirred in the solid state, such as friction welding. This is possible because stirring induces rotations of the existing subgrains in the existent microstructure [36], or the absorption of dislocations into sub-boundaries and the growth of subgrains [37].

\subsection{Mechanical properties}

Figure 5 presents microhardness measurements of the samples. It is noticeable that the curves are divided into two

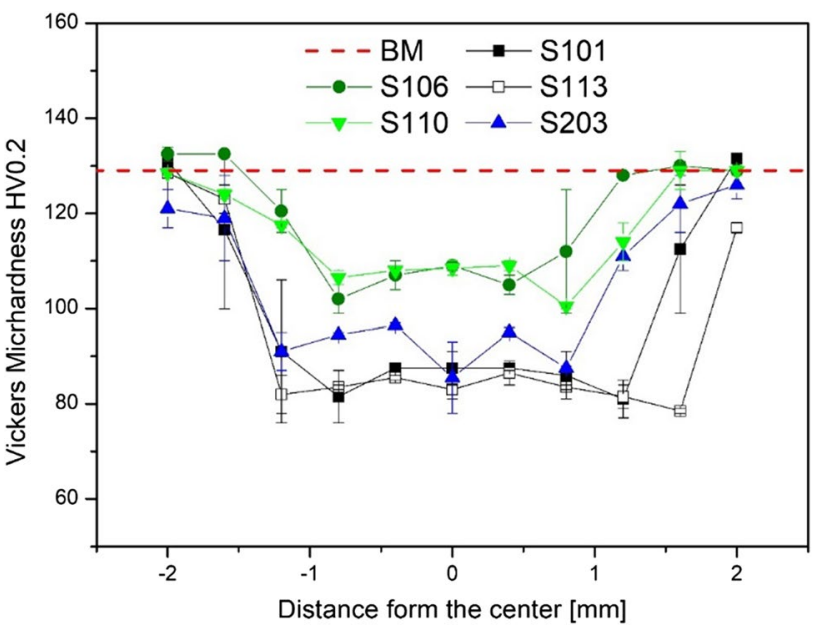

Fig. 5 Microhardness measurements performed in the weld zone, 0 indicates the centre of the weld

groups, i.e., S101, S113, S203, and S106, S110. The first group features a larger decrease in microhardness, from around $120-130 \mathrm{HV} 0.2$ to $80 \mathrm{HV} 0.2$, whereas in the second group the decrease was only to $100 \mathrm{HV} 0.2$. Additionally, for joints S106 and S110 a significant decrease is noticeable at a distance of $\pm 0.8 \mathrm{~mm}$ from the center, whereas for $\mathrm{S} 101$, $\mathrm{S} 113, \mathrm{~S} 203$ this occurs at $\pm 1.4 \mathrm{~mm}$. This indicates that the heat affected zone was larger for S101, S113, S203. Those joints were welded using $N=16,000-20,000 \mathrm{rpm}$, whereas S106 and S110 were made at a lower rotational speed of $13,000 \mathrm{rpm}$, which resulted in a shorter processing time and a lower heat input.

Figure 6 shows engineering stress-strain curves for the joints investigated. In comparison with the $\mathrm{BM}$, the welds are characterized by lower YS and UTS values, as shown in Table 2. However, there is a large dispersion of total elongation values, which is reduced for joints S106 and S110, 


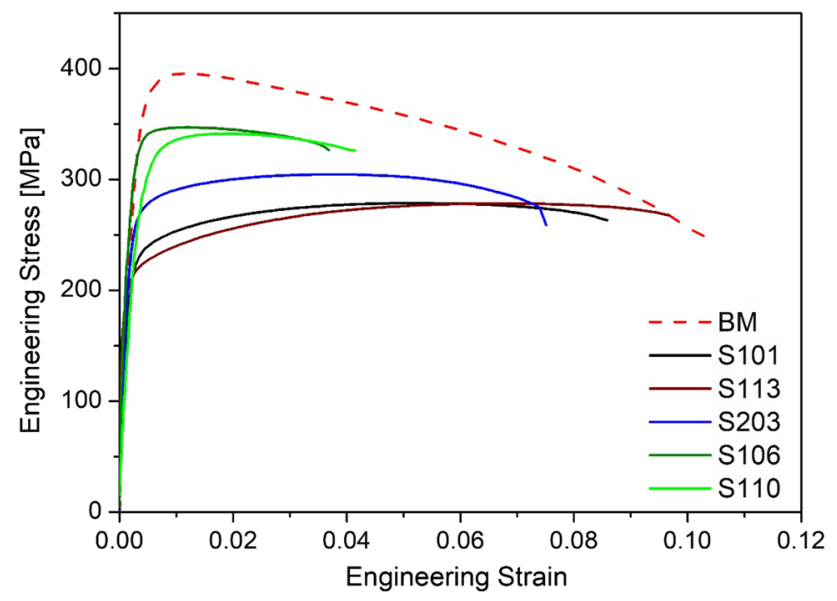

Fig. 6 Engineering stress-strain curves for the samples investigated

Table 2 Yield strength YS, ultimate tensile strength UTS and total elongation $\mathrm{El}$ and uniform elongation $\mathrm{El}_{\mathrm{u}}$ for the $\mathrm{BM}$ and welded samples

\begin{tabular}{|c|c|c|c|c|c|}
\hline No. & $\begin{array}{l}\text { Sample of } \\
\text { material }\end{array}$ & YS [MPa] & UTS [MPa] & $\mathrm{El}[\%]$ & $\mathrm{El}_{\mathrm{U}}[\%]$ \\
\hline 1 & $\mathrm{BM}$ & 361 & 396 & 10.5 & 1.2 \\
\hline 2 & S101 & 233 & 280 & 8.4 & 5.0 \\
\hline 3 & S113 & 214 & 277 & 9.6 & 6.6 \\
\hline 4 & S203 & 269 & 298 & 7.3 & 3.8 \\
\hline 5 & S106 & 332 & 358 & 3.5 & 1.2 \\
\hline 6 & S110 & 306 & 337 & 3.8 & 1.9 \\
\hline
\end{tabular}

or similar to the BM as for $\mathrm{S} 113$ and $\mathrm{S} 101$. The tensile test results presented are in accordance with the microhardness measurements. Joints that feature higher microhardness achieve larger YS and UTS values and reduced total elongation, while joints characterized by lower microhardness values reach larger total elongation and lower YS and UTS values, as generally observed in metallic materials. Discrepancies in the course of the tensile test curves and microhardness can be explained by the microstructural features. The joints characterized by smaller grain size similar to the BM, S106 and S110, have higher mechanical properties than those characterized by larger grain size, as described by the Hall-Petch relationship [38]. In Table 2, uniform elongation $\mathrm{El}_{\mathrm{U}}$ values are also presented. For the $\mathrm{BM}$, this value only reaches $1.2 \%$, which is typical for UFG materials, whose fast necking is caused by their limited capacity for strain accumulation [38]. Such a tendency is also visible in Fig. 7a, where strain maps of the tensile test specimens are shown. Figure 7b, c illustrates such maps for joints S113 and S106. In both cases, strain localizes at an early stage of straining in the weld zone, where failure subsequently occurs. Joints S106 and S110 are also characterized by limited uniform elongation values, which do not exceed $2 \%$. However, for joints $\mathrm{S} 101, \mathrm{~S} 113$ and $\mathrm{S} 203$, the $\mathrm{El}_{\mathrm{U}}$ value is notably larger. Since those joints are characterized by larger grain size and a lower amount of subgrains, their ability to accumulate plastic deformation increased and it was possible to acquire larger uniform and total elongations. In joint S113, the plastic deformation zone visible in Fig. $7 \mathrm{~b}$ is larger than that of joint S106 (Fig. 7c, in which strain quickly localizes. A similar effect during the friction welding of copper was observed in [39], where a HAZ characterized by lower mechanical properties was created near the thermomechanically affected region with enhanced mechanical strength, consequently reducing the mechanical properties of the material. Such a correlation for the investigated samples is presented in Fig. 8, where the energy and maximum heat power $Q$, defined by Eqs. 1 and 2, respectively, is plotted against YS. The YS increases with a decrease in both parameters, which indicates that limiting the heat input leads to greater mechanical strength. In this study, it was possible to decrease the heat by decreasing the rotational speed, the length of the friction phase, and the subsequent forging. Other studies show that similar results can be achieved by different approaches. In [40], friction welding was done under water; in [41], rapid cooling using liquid $\mathrm{CO}_{2}$ was used, which effectively reduced the temperature and resulted in a mechanical strength similar to or even higher than that of the base material.

\subsection{Corrosion resistance}

Prior to the PP measurements, the OCP was monitored for 1,800 s. OCP curves are shown in Fig. 9. For the BM, a distinct drop can be noticed during the first $600 \mathrm{~s}$ of immersion, followed by a more moderate further decrease. After 30 min of immersion, a drop in OCP from initial $-0.168 \mathrm{~V}$ to $-0.217 \mathrm{~V}$ was observed. When the potential drops very rapidly immediately after immersion, this may be caused by the dissolution of the copper native oxide layer and the formation of a $\mathrm{CuCl}$ layer [42]. For the $\mathrm{SZ}$ of the welds, there was also an observable continuous decrease of potential with time, although that decrease was less abrupt. The value of OCP after $30 \mathrm{~min}$ of immersion was higher than for the BM, and was in a range of $-0.189 \mathrm{~V}$ to $-0.205 \mathrm{~V}$. A higher OCP may indicate a better passivation effect, as shown by the formation of a more complex, denser passivation layer on the sample's surface [43]. For each weld, the SZ exhibited a higher OCP than that of the BM.

The representative PP curves recorded after 30-min immersion in the test solution are presented in Fig. 10. For all states, the curves do not change. For the BM, the values of corrosion potential $\left(E_{\text {corr }}\right)$ and corrosion current density $\left(I_{\text {corr }}\right)$ equal $-0.232 \mathrm{~V}$ and $1.5 \mu \mathrm{A} / \mathrm{cm}^{2}$, respectively. For all welds and for both zones, i.e., HAZ and SZ, a shift towards a higher potential was observed in comparison with the BM. 

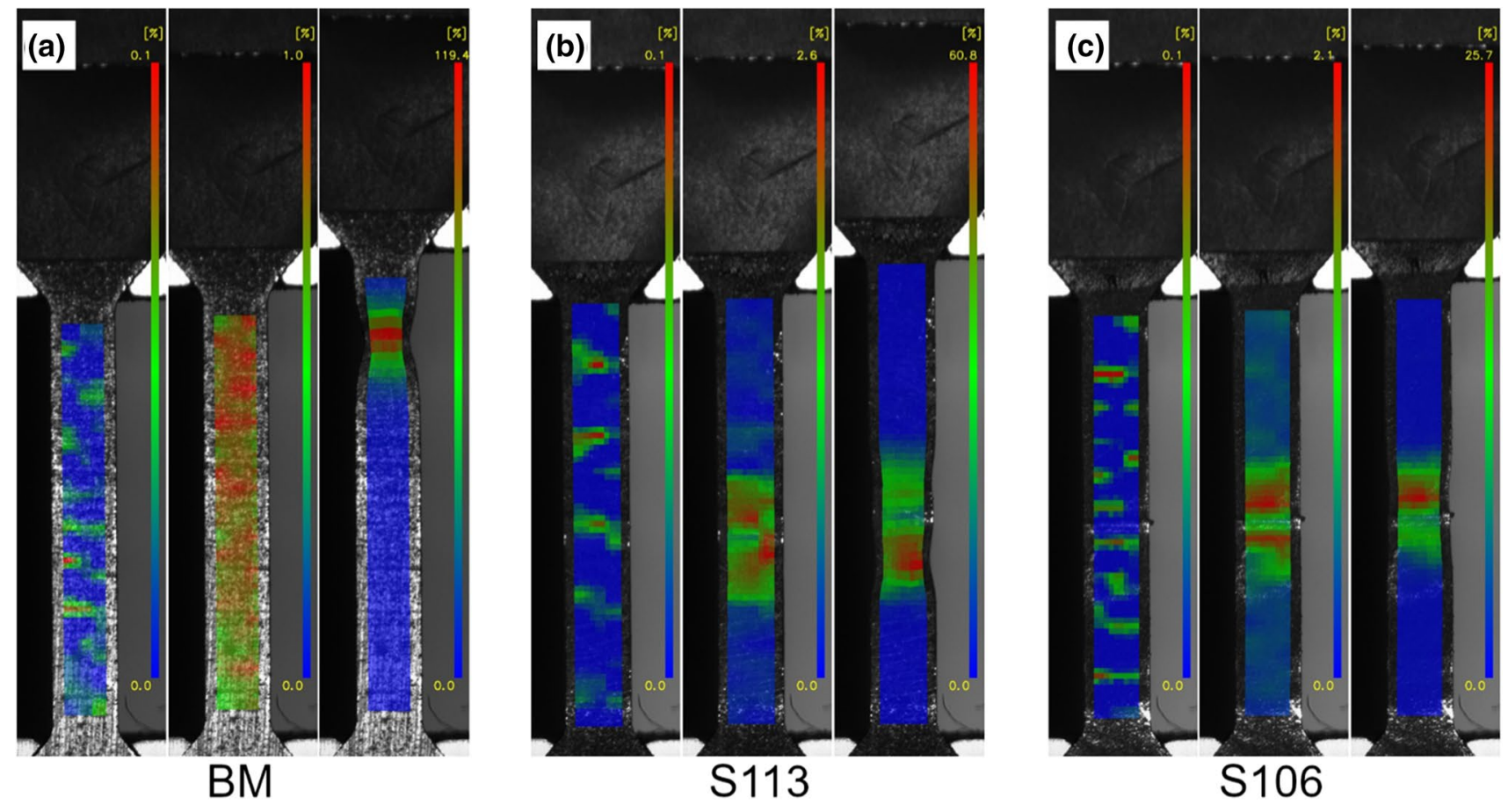

$0 \% \quad 1 \% \quad A=10.5 \%$

$0 \% \quad 1 \% \quad A=9.6 \%$

$0 \%$

$1 \%$

$A=3.5 \%$

Fig. 7 DIC strain maps of tensile elongation of samples BM (a), S113 (b) and S106 (c). For each sample, a strain map is shown for the initial condition, $1 \%$ strain and total elongation $\mathrm{A}$

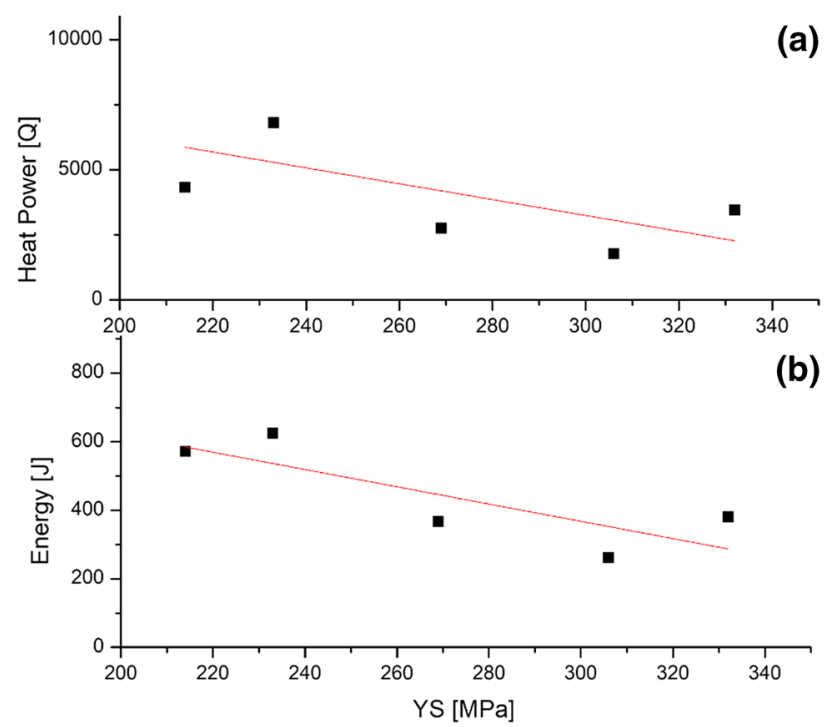

Fig. 8 Maximum heat power (a) and energy (b) as a function of YS

For joints S101, S203 and S110, the changes are relatively small and the increase in $E_{\text {corr }}$ is in a range of $10-30 \mathrm{mV}$. Also for these joints, there is no clear correlation between the HAZ and SZ. For the remaining joints, S113 and S106, the highest $E_{\text {corr }}$ was observed in the SZ, while the HAZ improved in relation to the $\mathrm{BM}$, but decreased slightly in

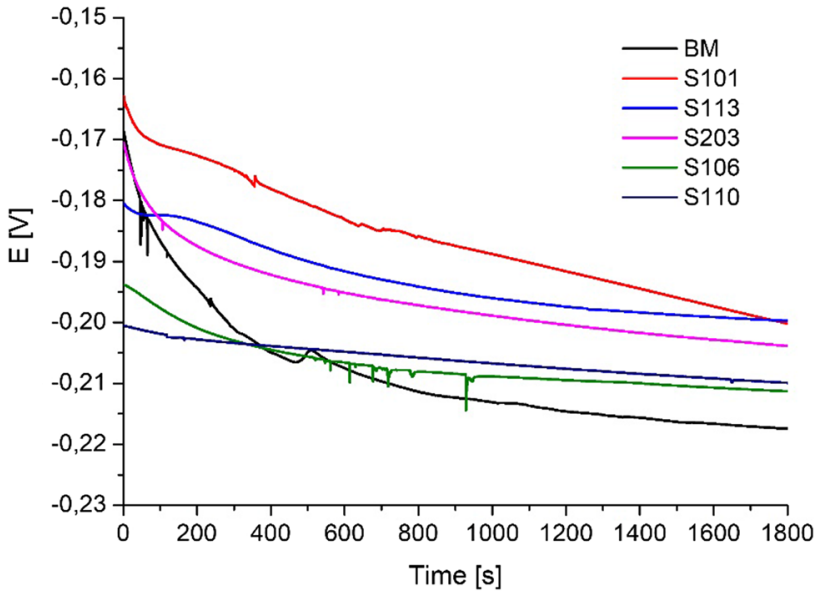

Fig. 9 OCP plots for the BM and weld stir zones during 30 min of exposure time in $3.5 \mathrm{wt} . \% \mathrm{NaCl}$

comparison with the SZ. Also, the shift towards higher potentials was more significant here than in the previously mentioned joints, and is estimated as being around $50 \mathrm{mV}$. The $I_{\text {corr }}$ parameter, which is commonly used for evaluating corrosion rate, varied for the joints investigated, and no clear correlation was identified. A drop in $I_{\text {corr }}$ is observed only in the SZ of joint S110, where its value equals $0.19 \mu \mathrm{A} /$ $\mathrm{cm}^{2}$. Moreover, for this joint the anodic current density was 

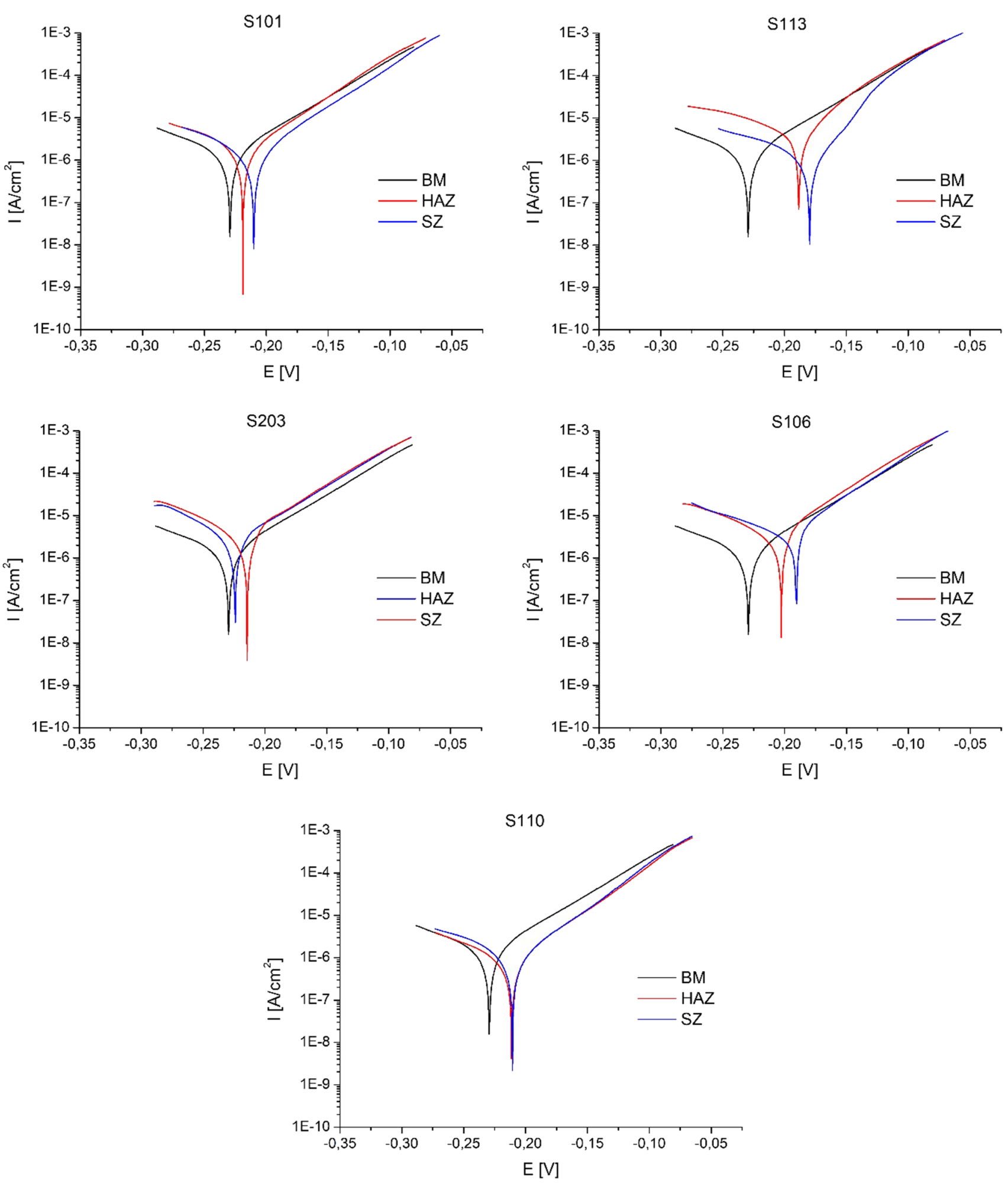

Fig. 10 PP curves of UFG copper welds recorded in $3.5 \mathrm{wt} . \% \mathrm{NaCl}$ bath

lower in the HAZ and SZ in comparison with the BM. For the other joints, the value of $I_{\text {corr }}$ remained at a comparable level or increased, with the highest value in the SZ being in joint $\mathrm{S} 106$, where that value was $4.5 \mu \mathrm{A} / \mathrm{cm}^{2}$.
Based on the $I_{\text {corr }}$ results, it is not possible to identify a clear correlation between corrosion resistance and the investigated areas of the welds. Only for joint S110 was a decrease observed, but even here the changes were not 
significant. However, when the OCP and $E_{\text {corr }}$ are taken into account, it can be stated that the SZ and HAZ reveal better resistance than the BM. The main change between a particular weld's zones is in grain size. When the influence of this parameter on the corrosion resistance of copper and its alloys was investigated, as shown in the review in [44], the results indicate that no single clear correlation occurs, and the results obtained depend on various factors, such as the chosen environment. In work [45] it was shown that a UFG microstructure in copper does not change the corrosion behavior in a qualitative manner. The main advantage of a UFG microstructure is its higher homogeneity and better resistance to localized attack. However, when pure copper was investigated in $3.5 \% \mathrm{NaCl}$, the grain refinement obtained by mtECAP caused an improvement in the corrosion and pitting potentials [24]. UFG copper had a higher corrosion rate than CG copper in Hank's solution [46]; however, the surface damage was more uniform, which could have been caused by the high number of grain boundaries - this tends to equilibrate the energies across the material.

The corrosion resistance of the welds from pure copper after friction stir welding (FSW) examined in 3.5wt.\% $\mathrm{NaCl}$ were investigated in [47]. It was noticed that FSW led to an improvement in the corrosion resistance in the SZ due to a grain refinement in this area. The conclusion was drawn that decreasing grain size has a beneficial effect on corrosion resistance. Similar observations were made in work [48], where the higher corrosion resistance of a nanograined $\mathrm{Cu}-\mathrm{Ni}$ alloy was attributed to the nanograined surface, which facilitates the formation of a passivation film on the surface during the corrosion process, and therefore can effectively prevent further corrosion. In the case of the investigated welds, the grain size in the SZ increased in most of them (see Fig. 4b) due to dynamic recrystallization in this area. Nevertheless, due to the applied process parameters, the grain growth was not significant. Based on these observations, it can be stated that the improvement in corrosion resistance must be connected with factors other than grain size. In the SZ, in every weld, the fraction of HAGBs was greater than in the BM. HAGBs may be the places where oxidation occurs, such that more of them may lead to better corrosion resistance. Moreover, from the literature review, it can be stated that better corrosion resistance can be also attributed to increased residual stresses. This has been shown for copper after laser shock peening, where the introduction of residual stresses resulted in an increased OCP after $1000 \mathrm{~s}$ immersion in $3.5 \% \mathrm{NaCl}$, but also shifted the $E_{\text {corr }}$ to nobler values in comparison with the untreated basal surface [49]. Although the topic of residual stresses in RFW process is not examined in detail in the present study, the values achieved in the SZ could be significant [2] and their influence should not be omitted, especially where conical foreheads were applied.

\section{Summary}

In the present work, the influence of processing parameters of Direct Drive Rotary Friction Welding on joints of UFG copper was presented. Copper rods were characterized by a UFG grain size of $0.7 \mu \mathrm{m}$. Depending on the processing conditions, i.e., the amount of energy and heat power generated during the process, various microstructures were created in the joint zone. A larger heat input, caused by a higher rotational speed and longer processing time, resulted in more significant grain growth of up to more than $1 \mu \mathrm{m}$, whereas a lower heat input made it possible to preserve grain size below this value. Microstructural features translate into mechanical properties. Larger grain size resulted in lower mechanical strength and larger elongation. Additionally, the samples welded in conditions with higher heat input regained strain hardening capacity leading to a higher uniform elongation, which is unlikely for UFG materials. The samples in which the UFG microstructure was preserved reached lower elongations than the BM due to a concentration of strain in the weld zone. The corrosion resistance in the stir zone increased, evident in the higher open circuit potential and corrosion potential in comparison with the BM. The observed differences were in a range of $50 \mathrm{mV}$. Those changes could be explained by the higher fraction of HAGBs in the SZ.

The results presented show the potential of the DD-RFW method for welding UFG copper rods without a dramatic loss in their mechanical properties and with unchanged or even enhanced corrosion resistance. High energy and short processing times result in sufficient bonding without an excessive overheating of the object that could lead to substantial grain growth. However, the typical approach of reducing heat input while welding using a conventional DD-RFW machine was not sufficient to control the welding process in the case of UFG copper. A special design of the geometry of the foreheads of the two welded rods was required. In this study, a conical forehead for the rotated rod was introduced, whereas the forehead of the stationary rod remained flat.

Funding The research leading to these results received funding from the National Science Centre, Poland under OPUS-14 Grant Agreement No UMO-2017/27/B/ST8/00349.

Materials and/or code availability The raw/processed data required to reproduce these findings cannot be shared at this time due to technical or time limitations.

\section{Declarations}

Conflicts of interest The authors have no conflicts of interest to declare that are relevant to the content of this article. 
Ethics approval Not applicable.

Informed consent Not applicable.

Open Access This article is licensed under a Creative Commons Attribution 4.0 International License, which permits use, sharing, adaptation, distribution and reproduction in any medium or format, as long as you give appropriate credit to the original author(s) and the source, provide a link to the Creative Commons licence, and indicate if changes were made. The images or other third party material in this article are included in the article's Creative Commons licence, unless indicated otherwise in a credit line to the material. If material is not included in the article's Creative Commons licence and your intended use is not permitted by statutory regulation or exceeds the permitted use, you will need to obtain permission directly from the copyright holder. To view a copy of this licence, visit http://creativecommons.org/licenses/by/4.0/.

\section{References}

1. Segal V. Equal-channel angular extrusion (ECAE): from a laboratory curiosity to an industrial technology. Metals (Basel). 2020;10:244

2. Li W, Vairis A, Preuss M, Ma T. Linear and rotary friction welding review. Int Mater Rev. 2016;61:71-100. https://doi.org/10. 1080/09506608.2015.1109214.

3. Nicholas ED. Friction Processing Technologies. Weld World. 2003;47:2-9.

4. Mirzadeh H. High strain rate superplasticity via friction stir processing (FSP): A review. Mater Sci Eng A. 2021;819: 141499. https://doi.org/10.1016/j.msea.2021.141499.

5. Kwon Y, Saito N, Shigematsu I. Friction stir process as a new manufacturing technique of ultrafine grained aluminum alloy. J Mater Sci Lett. 2002;21:1473-6.

6. Fujii H, Ueji R, Takada Y, Kitahara H, Tsuji N, Nakata K, Nogi $\mathrm{K}$. Friction stir welding of ultrafine grained interstitial free steels. Mater Trans. 2006;47:239-42.

7. Malopheyev S, Mironov S, Kulitskiy V, Kaibyshev R. Friction-stir welding of ultra-fine grained sheets of $\mathrm{Al}-\mathrm{Mg}-\mathrm{Sc}-\mathrm{Zr}$ alloy. Mater Sci Eng A. 2015;624:132-9. https://doi.org/10.1016/j.msea.2014. 11.079 .

8. Sahin M, Akata HE, Ozel K. An experimental study on joining of severe plastic deformed aluminium materials with friction welding method. Mater Des. 2008;29:265-74. https://doi.org/10.1016/j. matdes.2006.11.004.

9. Zhang B, Yuan S, Wang X. Friction stir welding of AZ31 magnesium alloys processed by equal channel angular. Rare Met. 2008;27:393-9.

10. Sato YS, Urata M, Kokawa H, Ikeda K. Hall-Petch relationship in friction stir welds of equal channel angular-pressed aluminium alloys. Mater Sci Eng A. 2003;354:298-305. https://doi.org/10. 1016/S0921-5093(03)00008-X.

11. Ouyang J, Yarrapareddy E, Kovacevic R. Microstructural evolution in the friction stir welded 6061 aluminum alloy (T6-temper condition ) to copper. J Mater Process Technl. 2006;172:110-22. https://doi.org/10.1016/j.jmatprotec.2005.09.013.

12. Barekatain H, Kazeminezhad M, Kokabi AH. Microstructure and mechanical properties in dissimilar butt friction stir welding of severely plastic deformed aluminum AA 1050 and commercially pure copper sheets. J Mater Sci Technol. 2014;30:826-34. https:// doi.org/10.1016/j.jmst.2013.11.007.

13. Xue P, Wang BB, Chen FF, Wang WG, Xiao BL, Ma ZY. Microstructure and mechanical properties of friction stir processed
$\mathrm{Cu}$ with an ideal ultra fi ne-grained structure. Mater Charact. 2016;121:187-94. https://doi.org/10.1016/j.matchar.2016.10.009.

14. Prangnell PB, Bowen JR, Apps PJ. Ultra-fine grain structures in aluminium alloys by severe deformation processing. Mater Sci Eng A. 2004;375-377:178-85.

15. Su J, Nelson TW, Sterling CJ. Friction stir processing of large-area bulk UFG aluminum alloys. Scr Mater. 2005;52:135-40. https:// doi.org/10.1016/j.scriptamat.2004.09.014.

16. Xie GM, Ma ZY, Geng L. Development of a fine-grained microstructure and the properties of a nugget zone in friction stir welded pure copper. Scr Mater. 2007;57:73-6. https://doi.org/10.1016/j. scriptamat.2007.03.048.

17. Xu N, Song Q, Bao Y, Jiang Y, Shen J. Achieving good strengthductility synergy of friction stir welded $\mathrm{Cu}$ joint by using large load with extremely low welding speed and rotation rate. Mater Sci Eng A. 2017;687:73-81. https://doi.org/10.1016/j.msea.2017. 01.052.

18. Xue P, Xiao BL, Zhang Q, Ma ZY. Achieving friction stir welded pure copper joints with nearly equal strength to the parent metal via additional rapid cooling. Scr Mater. 2011;64:1051-4. https:// doi.org/10.1016/j.scriptamat.2011.02.019.

19. Davari H, Parsa MH, Hadian AM, Ahmadabadi MN, Davari H, Parsa MH, Hadian AM, Ahmadabadi MN. Experimental and numerical thermomechanical analysis of hybrid friction welding of commercially pure copper bars experimental and numerical thermomechanical analysis of hybrid friction welding of commercially pure copper bars. Mater Manuf Process. 2011;26:694-702. https://doi.org/10.1080/10426914.2010.480993.

20. Uday MB, Fauzi MNA, Zuhailawati H, Ismail AB. Advances in friction welding process: a review. Sci Technol Weld Join. 2010;15:534-59. https://doi.org/10.1179/136217110X12785 889550064.

21. Yang Y, Chen W, Lee H. A nonlinear inverse problem in estimating the heat generation in rotary friction welding. Numer Heat Transf Part A Appl Int J Comput Methodol. 2011;59(2):130-49. https://doi.org/10.1080/10407782.2011.540965.

22. Rosochowski A, Olejnik L. Numerical and physical modelling of plastic deformation in 2-turn equal channel angular extrusion. J Mater Process Technol. 2002;126:309-16.

23. Olejnik L, Rosochowski A. Scaled-up ECAP with enhanced productivity. Steel Res Int. 2008;2:439-47.

24. Lipińska M, Olejnik L, Lewandowska M. The influence of an ECAP-based deformation process on the microstructure and properties of electrolytic tough pitch copper. Metals (Basel). 2018;53:3862-75. https://doi.org/10.1007/s10853-017-1814-y.

25. Rosochowski A. Severe plastic deformation technology. Dunbeath: Whittles Publishing; 2017.

26. Morawiński Ł, Jasiński C, Ciemiorek M, Chmielewski T, Olejnik L, Lewandowska M. Solid-state welding of ultrafine grained copper rods. Arch Civ Mech Eng. 2021;21:89. https://doi.org/10. 1007/s43452-021-00244-0.

27. Mishra A, Kad BK, Gregori F, Meyers MA. Microstructural evolution in copper subjected to severe plastic deformation: experiments and analysis. Acta Mater. 2007;55:13-28.

28. Molodova X, Gottstein G, Winning M, Hellmig RJ. Thermal stability of ECAP processed pure copper. Mater Sci Eng A. 2007;461:204-13.

29. Sakai T, Belyakov A, Kaibyshev R, Miura H, Jonas JJ. Dynamic and post-dynamic recrystallization under hot, cold and severe plastic deformation conditions. Prog Mater Sci. 2014;60:130-207. https://doi.org/10.1016/j.pmatsci.2013.09.002.

30. Heidarzadeh A, Mironov S, Kaibyshev R, Çam G, Simar A, Gerlich A, Withers J. Friction stir welding/processing of metals and alloys : A comprehensive review on microstructural evolution. Prog Mater Sci. 2021;117: 100752. https://doi.org/10.1016/j. pmatsci.2020.100752. 
31. Patel V, Li W, Vairis A, Badheka V. Recent development in friction stir processing as a solid-state grain refinement technique: microstructural evolution and property enhancement recent development in friction stir processing as a solid-state grain refinement technique: microstructural evolution and property enhancement. Crit Rev Solid State Mater Sci. 2019;44:378-426. https://doi.org/ 10.1080/10408436.2018.1490251.

32. Xue P, Wang BB, Chen FF, Wang WG, Xiao BL, Ma ZY. Microstructure and mechanical properties of friction stir processed $\mathrm{Cu}$ with an ideal ultra fine-grained structure. Mater Charact. 2016;121:187-94. https://doi.org/10.1016/j.matchar.2016.10.009.

33. Li W, Wang F. Modeling of continuous drive friction welding of mild steel. Mater Sci Eng A. 2011;528:5921-6. https://doi.org/10. 1016/j.msea.2011.04.001

34. Maalekian M, Kozeschnik E, Brantner HP, Cerjak H. Comparative analysis of heat generation in friction welding of steel bars. Acta Mater. 2008;56:2843-55. https://doi.org/10.1016/j.actamat.2008. 02.016 .

35. Duffin FD, Bahrani A. Frictional behaviour of mild steel in friction welding. Wear. 1973;26:53-74

36. Jata KV, Semiatin SL. Continuous dynamic recrystallization during friction stir welding of high strength aluminium alloys. Scr Mater. 2000;43:743-9.

37. Su J, Nelson TW, Mishra R, Mahoney M. Microstructural investigation of friction stir welded 7050-T651 aluminium. Acta Mater. 2003;51:713-29. https://doi.org/10.1016/S1359-6454(02) 00449-4.

38. Meyers MA, Mishra A, Benson DJ. Mechanical properties of nanocrystalline materials. Prog Mater Sci. 2006;51:427-556. https://doi.org/10.1016/j.pmatsci.2005.08.003.

39. Barenji RV. Influence of heat input conditions on microstructure evolution and mechanical properties of friction stir welded pure copper joints. Trans Indian Inst Met. 2016;69:1077-85. https:// doi.org/10.1007/s12666-015-0624-7.

40. Farrokhi H, Heidarzadeh A, Saeid T. Frictions stir welding of copper under different welding parameters and media. Sci Technol Weld Join. 2013;18:697-702. https://doi.org/10.1179/13621 71813Y.0000000148.

41. Xu N, Ueji R, Fujii H. Enhanced mechanical properties of 70/30 brass joint by rapid cooling friction stir welding. Mater Sci Eng A. 2014;610:132-8. https://doi.org/10.1016/j.msea.2014.05.037.
42. Tasic ZZ, Petrovic Mihajlovic MB, Radovanovic MB, Simonovic AT, Antonijevic MM. Cephradine as corrosion inhibitor for copper in $0.9 \% \mathrm{NaCl}$ solution. J Mol Struct. 2018;1159:46-54. https:// doi.org/10.1016/j.molstruc.2018.01.031.

43. Song D, Ma A, Sun W, Jiang J, Jiang J, Yang D, Guo G. Improved corrosion resistance in simulated concrete pore solution of surface nanocrystallized rebar fabricated by wire-brushing. Corros Sci. 2014;82:437-41. https://doi.org/10.1016/j.corsci.2014.01.034.

44. Ralston KD, Birbilis N. Effect of grain size on corrosion: a REVIEW. Corrosion. 2010;66:1-4. https://doi.org/10.5006/1. 3462912.

45. Vinogradov A, Mimaki T, Hashimoto S, Valiev R. On the corrosion behaviour of ultra-fine grain copper. Scr Mater. 1999;41:319-26.

46. Xu XX, Nie FL, Zhang JX, Zheng W, Zheng YF, Hu C, Yang G. Corrosion and ion release behavior of ultra-fi ne grained bulk pure copper fabricated by ECAP in Hanks solution as potential biomaterial for contraception. Mater Lett. 2010;64:524-7. https:// doi.org/10.1016/j.matlet.2009.11.065.

47. Fattah-alhosseini A, Taheri AH. Effect of friction stir welding on corrosion behavior of pure copper in $3.5 \mathrm{wt} . \% \mathrm{NaCl}$ solution. $\mathrm{J}$ Manuf Process. 2015;20:98-103. https://doi.org/10.1016/j.jmapro. 2015.09.005.

48. Xia T, Zeng L, Zhang X, Liu J, Zhang W, Liang T. Enhanced corrosion resistance of a $\mathrm{Cu}$ e $10 \mathrm{Ni}$ alloy in a $3.5 \mathrm{wt} \% \mathrm{NaCl}$ solution by means of ultrasonic surface rolling treatment. Surf Coat Technol. 2019;363:390-9. https://doi.org/10.1016/j.surfcoat.2019. 02.039 .

49. Chukwuike VI, Echem OG, Prabhakaran S, Anandkumar S, Barik RC. Laser shock peening (LSP): electrochemical and hydrodynamic investigation of corrosion protection pre-treatment for a copper surface in $3.5 \% \mathrm{NaCl}$ medium. Corros Sci. 2021;179:109156. https://doi.org/10.1016/j.corsci.2020.109156.

Publisher's Note Springer Nature remains neutral with regard to jurisdictional claims in published maps and institutional affiliations. 